\title{
Quantitative analysis of tissue regeneration after use of chitosan membrane versus collagen membrane in the management of grade II furcation defects in dogs
}

Fatma M Boker ${ }^{1}$, Maha A Abou-Khadr², Hanna S Raslan³, Rania A Fahmy ${ }^{4}$

\begin{abstract}
INTRODUCTION: Involvement of the furcations of multirooted teeth represents a challenge in the treatment of periodontal disease, both from a prognostic perspective and from the perspective of therapeutic measures.

OBJECTIVES: the current investigation was conducted to evaluate the regenerative potential of chitosan membrane in the management of critical size grade II furcation defects and to compare it with conventional therapy using collagen membrane.

MATERIALS AND METHODS: A total number of four adult systemically healthy mongrel dogs were included in the current study. Grade II critical-sized furcation defects were surgically created with respect to lower premolar teeth. In all four dogs, the right quadrants received chitosan membrane with natural hydroxyapatite. Whereas, the left quadrants received collagen membrane with natural hydroxyapatite.

RESULTS: The present study observed that chitosan was better than collagen regarding mean bone surface area $(\mathrm{P}<0.05)$ and the difference was statistically significant.

CONCLUSIONS: Chitosan membrane is an effective, easy to handle, cheap membrane that can be used in periodontal regeneration of furcation defects. Chitosan membrane showed superior periodontal tissue regeneration when compared to collagen membrane in the mangement of such defects.
\end{abstract}

KEY WORDS: chitosan, collagen, tissue regeneration, furcation defects

1- B.D.S. Faculty of Dentistry Benghazi University, Libya

2- Professor of Periodontology, Oral Medicine, Oral Diagnosis and Radiology Alexandria university, Egypt.

3- Professor of Oral Pathology

4- Lecturer of Periodontology, Oral Medicine, Oral Diagnosis and Radiology Alexandria university, Egypt.

\section{INTRODUCTION}

The term "periodontal disease" in its strictest sense refers to both gingivitis and periodontitis (1). Periodontitis is a disease of the periodontium characterized by irreversible loss of connective tissue attachment and supporting alveolar bone. These changes often lead to an aesthetically and functionally compromised dentition. For many decades, periodontists have been interested in regenerating tissues destroyed by periodontitis (2).

Over the years, the treatment of periodontal diseases associated with attachment loss has involved numerous surgical and nonsurgical approaches (3). The management of furcation involvement presents one of the greatest challenges in periodontal therapy. Furcation involved molar teeth respond less favorably to conventional periodontal therapy than non-involved molar or non-molar teeth (4).

New treatment modalities for osseous defects have been introduced during the last two decades, with the prime objective of enhancing the regeneration of periodontal tissue. These include the use of bone substitutes and guided tissue regeneration (GTR) using membrane techniques(5,6,7).

Clinical studies have shown that guided tissue regeneration (GTR) can improve the response of advanced grade II furcation defects to therapy by means of pocket reduction, gain in clinical attachment levels and bone defect fill. The improvement in these clinical parameters plus the potential of creating new attachment leads to the consideration of GTR as the treatment of choice in this type of periodontal defect. GTR has offered better results than open-flap debridement or bone replacement grafts alone in mandibular grade II furcation (8).

GTR is effective in halting tissue and bone destruction and promoting new tissue and bone formation (9). A physical barrier (membrane) with appropriate shape and position is placed to cover the area in which the regenerative process is to take place. The membranes exclude unwanted epithelial and gingival connective tissue cells from the healing area and allow (guided) periodontal ligament (PDL) cells to repopulate the detached root surface. The membrane barriers have also been applied in the regeneration of bone surrounding peri-implant defects, which is defined as guided bone regeneration (GBR) (10).

The membranes used in GTR and GBR are divided into nonabsorbable membranes and bioabsorbable membranes. There is an increase in the use of bioabsorable membranes as second-stage surgeries are not required for membrane removal (11). Bioabsorbable membranes are made of a wide variety of materials, including collagen, polylactic acid, polyurethane, and chitosan (12).

Chitosan is a deacetylated derivative of chitin (the chitin was isolated from shrimp shells.) Chitosan is a natural biopolymer with a potential application in the tissue engineering and drug delivery fields, composed by (1-4)linked D-glucosamine and N-Acetyl-D-glucosamine. This biopolymer is obtained through the deacetylation of chitin, one of the most abundant naturally occurring polysaccharides and a waste material of the seafood industry (13).

Chitosan is a biocompatible, biodegradable, and antimicrobial material. It acts as a hydrating agent and possesses tissue healing and osteoinducing effect. Chitosan can be easily processed into membranes, gels, nanofibers, beads, nanoparticles, scaffolds, and sponge forms and can be used in drug delivery systems (14). It has also been used as a bone scaffold material and barrier membrane owing to its osteoinduction / osteoconduction properties $(15,16)$.

Collagen-based membranes revealed good clinical results, however, there are still some practical problems associated with them, such as poor mechanical strength, fast degradation, and high cost (17). Regarding the pure chitosan 
membranes, they are relatively inexpensive and show much higher mechanical strength compared to collagen membranes $(18,19)$.

To the best of our knowledge this material has not been tested to manage advanced grade II furcation defects in dogs. Therefore, it would be interesting to evaluate the use of this material in these defects and compare it to a more conventional therapeutic approach.

Therefore, the aim of this study was to conduct quantitative analysis of tissue regeneration after the use of chitosan membrane versus collagen membrane in the management of grade II furcation defects in dogs

\section{MATERIAL AND METHODS I- METHODS}

A comparative study was carried out on a total of 4 male mongrel dogs (Canis familaris). The dogs were about 17-24 months old, weighting approximately $18-24 \mathrm{~kg}$, all dogs were systemically healthy. The mandibular third (P3) and fourth (P4) premolars were selected for this study.

The study was approved by the research ethics committee, faculty of dentistry, Alexandria University.

\section{The study included two groups as follows}

GROUP I: (experimental group) included 8 surgically created critical-sized, grade II furcation defects in the right mandibular premolars. Defects were managed with natural hydroxyapatite and chitosan membrane.

GROUP II: (control group) included 8 surgically created critical-sized, grade II furcation defects in left mandibular premolars. Defects were managed with natural hydroxyapatite and collagen membrane.

\section{II-MATERIALS}

A- Chitosan Membrane (Chitosan M. W. Cognis)

- Supplied in a single use, sterile pack

B-Natural hydroxyapatite (Euro-Oss)

- It is a natural hydroxyapatite (HA), $600-250 \mu$ in size and $1 \mathrm{~g}$ in weight.

- Material is supplied in a sterile single usage vial

C - Collagen membrane (BIOMEND)

- Type I Bovine Collagen 20mm x 30mm.

- Absorbable and biocompatible membrane.

- Supplied in a single use, sterile pack.

\section{Surgical Procedure}

1) Four dogs were used in this study (16 sites, 8 for each group).

2) The animals were anesthetized using ketamine $10 \%$.

3) Sulcular incisions were taken and mucoperiosteal flaps were raised buccally at mandibular third and fourth premolar region in the right and left jaw quadrant.

4) Four grade II critical-sized furcation defects were created in mandibular premolars of each dog; defects were about (3 $\mathrm{mm}$ in depth $\mathrm{x} 4 \mathrm{~mm}$ in height) and (3.5 $\mathrm{mm}$ in depth $\mathrm{x} 4.5$ $\mathrm{mm}$ in height) in P3 and P4 respectively (20).

- Bone removal was performed using rotary burs with copious irrigation using sterile saline.

- Cementum was removed from the roots in defect sites to mimic naturally occurring defects.

5) The exposed root surfaces of the experimental teeth were carefully planned, thoroughly flushed with sterile saline and blotted dry with sterile gauze.

6) A reference notch was made on the root surface using a 0.5 $\mathrm{mm}$ round head bur to determine the most apical level of the defect and serve as histological reference point, later on.
7) Defects in right mandibular premolars were managed with natural hydroxyapatite and chitosan membrane. Defects in left mandibular premolars were managed with natural hydroxyapatite and collagen membrane.

8) Closure of the wound area was performed with interrupted suturing, using 2-0 silk sutures. Once sutured, sterile gauze with saline was applied on surgical site for two minutes to prevent tissue gaping. (Figures 1 and 2)

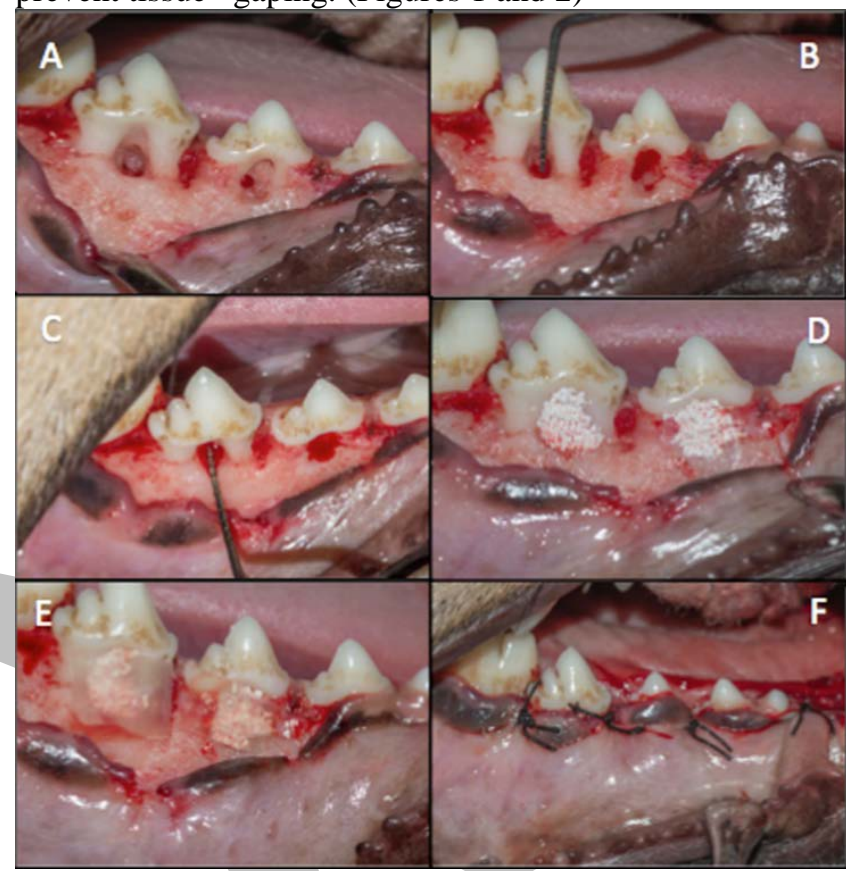

Figure (1): (A) Surgical defects created in right third and fourth premolar (B) Measuring the length of the furcation defect in the fourth premolar. (C) Measuring the depth of the furcation defect in the fourth premolar. (D) Placement of HA at the surgically created defects in right P3 and P4. (E) Placement of chitosan membrane over the grafted area. (F) Interrupted sutures and complete gingival coverage of the regenerative materials

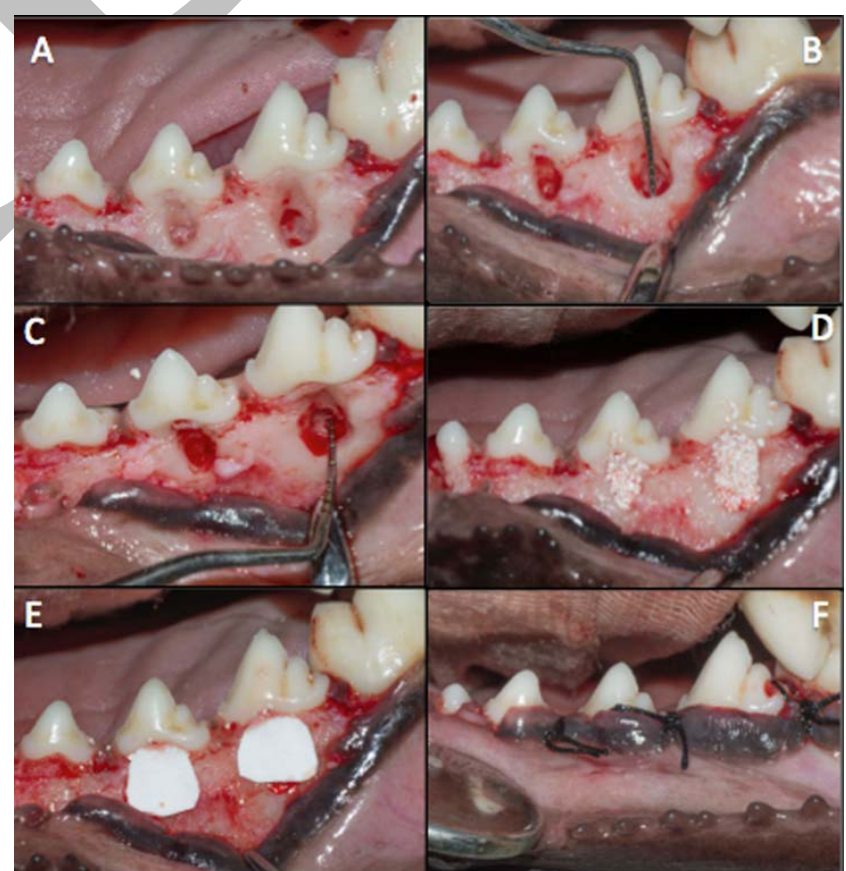

Figure (2): (A) Surgical defects created in left third and fourth premolar. (B) Measuring the length of the furcation defect in the fourth premolar. (C) Measuring the depth of the furcation defect in the fourth premolar. (D) Placement of HA at the surgically created defects in left P3 and P4. (E) Placement of collagen membrane over the grafted area. (F) Interrupted sutures and complete gingival coverage of the regenerative materials. 


\section{Postoperative care}

All animals received:

- Antibiotic (Ampiciillin 1 gm, Eipico, Egypt) intramuscular in the first day then mixed with dog's food for seven days.

- Non-steroidal anti-inflammatory (Brufen 600 mg, Abbot $\mathrm{GmbH}$, Germany) was also given IV in the first day postoperative. The dogs were placed on soft diet throughout the postoperative period to reduce the possibility of local trauma to the site of operation.

- The animals were observed daily for the first week for presence of infection and signs of inflammation.

9) The animals were sacrificed according to the following order:

- Two animals, 4 weeks after surgery.

- Two animals, 8 weeks post-surgically.

Scarification was done with an intravenous overdose injection of anesthesia (Concentrated sodium thiopental 500 mg, Archimedes Pharma, UK).

\section{Quantitative analysis of tissue regeneration}

Histological photomicrographs were quantitatively analyzed using image J $1.46 \mathrm{r}$ software (21) (all obtained at x100 original magnification). The parameters of interest were measured for test and control groups after 4 and 8 weeks of treatment. Measurements were finally averaged and standard deviation (SD) was calculated.

Steps of measuring bone surface area:

- Three sections of tissue from different standardized depths were used for quantification from each sample.

- Three photographs were taken from each section using the same magnification power.

- A rectangle with standardized dimensions was drawn on the desired area to be measured using the image J program.

- The surface area of this selected region was measured by choosing a region of interest (ROI) manager, from tools from the analyze menu, and the measurement was recorded.

- The surface area occupied by the bone trabeculae was selected using the wand tracing tool and the measurement was recorded. Its percentage to the total area selected was calculated.

- The measurements from three photographs were recorded and their mean was calculated for each of the three sections obtained, from each specimen.

The parameters of interest were measured for test and control groups after 4 and 8 weeks of treatment. Measurements were finally averaged and standard deviation (SD) was calculated. (Figure 3)

\section{STATISTICAL ANALYSIS}

Data were fed to a computer and analyzed using IBM SPSS software package version 20.0(22). Quantitative data were described using range (minimum and maximum), mean, standard deviation and median. Significance of the obtained results was judged at the $5 \%$ level.

Mann Whitney test was used to assess abnormal quantitative variables; to compare between two studied groups (23).

\section{RESULTS}

The aim of the present study was to evaluate the regenerative potential of chitosan membrane (experimental group) and collagen membrane (control group) in the management of bone defects at the furcation area at intervals of 4 and 8 weeks.

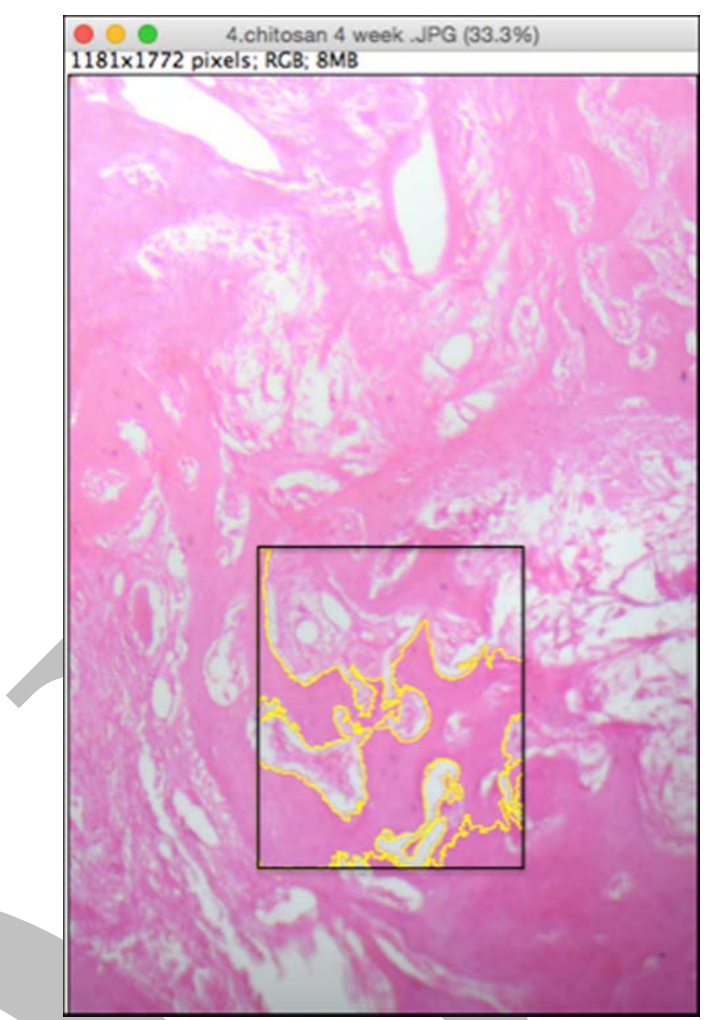

Figure (3): measuring bone surface area using image $\mathrm{J}$ 1.46r software.

A total of 4 male mongrel dogs, about 18-24 months old, weighting approximately $18-24 \mathrm{~kg}$, were included in the study. All dogs were systemically healthy. After completion of surgical procedures, sacrifice was timed for 2 dogs after 4 weeks and the remaining 2 dogs after 8 weeks' interval.

Following surgery, no adverse reactions such as allergies or postoperative infection were noted. No exposure or gingival recession was observed.

Following sacrifice, the jaws were sectioned and the resultant tissue blocks of the experimental teeth and surrounding tissue were removed with an electric saw.

Sixteen teeth with their surrounding periodontal tissues were dissected and further fixed by immersion in $10 \%$ neutral buffered formalin for 48hours. After 48hours of fixation, the specimens were washed and then decalcified in 5\% neutral buffered EDTA for 3 to 4 months. Decalcified specimens were sectioned $7 \mu \mathrm{m}$ thick and stained with hematoxylin solution and eosin and trichrome stains.

Descriptive histological result showed a distinctive amount of vascularization and regeneration potential in chitosan group regarding bone maturity.

\section{Quantitative analysis of tissue regeneration results}

The comparison between the two studied groups regarding newly formed bone area showed that in group I: At 4 weeks the mean value of newly formed bone area was (39.39\%) and at 8 weeks was $(65.30 \%)$. (Table 1$)$

In group II: At 4 weeks the mean value of newly formed bone area was $(11.70 \%)$ and at 8 weeks was $(31.13 \%)$. (Table 2)

Comparing the newly formed bone in each group the study showed that; in group I (Chitosan group) there was significant increase of mean value of newly formed bone area between the 2 study intervals $(\mathrm{P}=0.007)$. Also in group II (collagen group) there was significant increase of mean value of newly formed bone area between the 2 study intervals $(\mathrm{P}=0.035)$ 
Table (1): Bone surface area in group I during the 2 study intervals

\begin{tabular}{|c|c|c|}
\hline \multirow{2}{*}{} & \multicolumn{2}{|c|}{ Chitosan membrane experimental group } \\
\cline { 2 - 3 } & $\begin{array}{c}\text { 4 weeks } \\
(\mathrm{n}=7)\end{array}$ & $\begin{array}{c}\text { 8 weeks } \\
(\mathrm{n}=7)\end{array}$ \\
\hline Bone surface area & & \\
Min. - Max. & $18.90-63.10$ & $50.60-72.30$ \\
Mean \pm SD. & $39.39 \pm 15.89$ & $65.30 \pm 7.48$ \\
Median & 42.50 & 67.20 \\
\hline $\mathbf{Z}(\mathbf{p})$ & \multicolumn{2}{|c|}{$2.686^{\circ}\left(0.007^{\circ}\right)$} \\
\hline
\end{tabular}

Z: $Z$ for Mann Whitney test

*: Statistically significant at $\mathrm{p} \leq 0.05$

Table (2): Bone surface area in group II during the 2 study intervals

\begin{tabular}{|c|c|c|}
\hline \multirow{2}{*}{} & \multicolumn{2}{|c|}{ Collagen membrane control group } \\
\cline { 2 - 3 } & $\begin{array}{c}\text { 4 weeks } \\
(\mathbf{n}=7)\end{array}$ & $\begin{array}{c}\mathbf{8} \text { weeks } \\
(\mathbf{n}=7)\end{array}$ \\
\hline Bone surface area & & $5.80-50.90$ \\
Min. - Max. & $2.70-31.10$ & $31.13 \pm 15.01$ \\
Mean \pm SD. & $11.70 \pm 10.61$ & 28.30 \\
Median & 7.30 & $2.108^{*}\left(0.035^{\circ}\right)$ \\
\hline $\mathbf{Z}(\mathbf{p})$ & \multicolumn{2}{|c|}{} \\
\hline
\end{tabular}

Z: Z for Mann Whitney test

*: Statistically significant at $\mathrm{p} \leq 0.05$

When the mean value of newly formed bone surface areas were compared between the two groups, group I showed statistically significant superior results at 4 and 8 weeks $(\mathrm{P}=0.009)$ and $(\mathrm{P}=0.003)$, respectively. (Table3, Figure 4$)$

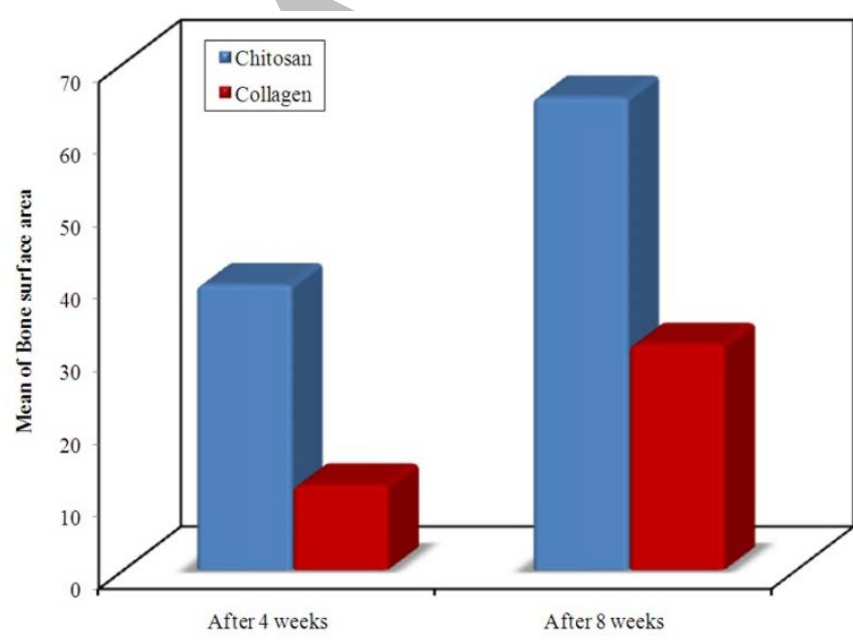

Figure (4): Comparison between the two studied groups according to bone surface area after 4 weeks and after 8 weeks.

\section{DISCUSSION}

The present study was carried out to evaluate the efficacy of chitosan membrane in the management of grade II furcation defects as regards to the enhancement of periodontal regeneration, using GTR approach.

The study comprised two groups: group I (experimental group) included 8 surgically created critical-sized, grade II furcation defects in right mandibular premolars. Defects were managed with natural hydroxyapatite and chitosan membrane, group II (control group) included 8 surgically created critical-sized, grade II furcation defects in left mandibular premolars. Defects were managed with natural hydroxyapatite and collagen membrane

Table (3): Comparison between the two studied groups according to $\%$ of bone surface area during the 2 study intervals

\begin{tabular}{||c|c|c||}
\hline \multirow{2}{*}{} & \multicolumn{2}{|c||}{ After 4 weeks } \\
\cline { 2 - 3 } & $\begin{array}{c}\text { Chitosan } \\
(\mathbf{n}=7)\end{array}$ & $\begin{array}{c}\text { Collagen } \\
(\mathbf{n}=7)\end{array}$ \\
\hline Bone surface area & & $2.70-31.10$ \\
Min. - Max. & $18.90-63.10$ & $11.70 \pm 10.61$ \\
Mean \pm SD. & $39.39 \pm 15.89$ & 7.30 \\
Median & 42.50 & $2.619^{*}\left(0.009^{\circ}\right)$ \\
\hline Z(p) & \multicolumn{2}{|c||}{ After 8 weeks } \\
\hline \multirow{2}{*}{ Bone surface area } & \multicolumn{2}{|c||}{$\begin{array}{c}\text { Collagen } \\
\text { (n=7) }\end{array}$} \\
Min. - Max. & $50.60-75.30$ & $5.80-50.90$ \\
Mean \pm SD & $65.30 \pm 7.48$ & $31.13 \pm 15.01$ \\
Median & 67.20 & 28.30 \\
\cline { 2 - 3 } & \multicolumn{2}{|c||}{$3.003^{\circ}\left(0.003^{\circ}\right)$} \\
\hline Z(p) & \multicolumn{2}{|c||}{} \\
\hline
\end{tabular}

$\mathrm{Z}: \mathrm{Z}$ for Mann Whitney test

*: Statistically significant at $\mathrm{p} \leq 0.05$

In the current study "critical-sized" furcation involvement defects have been used. The critical sized defect has been defined as "the smallest defect in a particular bone and species of an animal that will not heal spontaneously during the lifetime of the animal" (24). Hence, one can conclude that such a defects are wellcharacterized, standardized wound models that are reproducible. This allowed for unbiased and appropriate strategy for analysis of the obtained results (25).

In this study the bone surface area was assessed by image $\mathrm{J}$ in the two groups at the end of the first month. There was an increase in mean bone surface area levels between chitosan group and collagen group, it was statistically significant $(\mathrm{P}<0.05)$. There was also statistically significant increase between the two groups in the end of second month $(\mathrm{P}<0.05)$.

This was in accordance to several studies that reported favorable results regarding the use of chitosan in bone stimulation.

Pang et al (26) compared chitosan / absorbable collagen sponge (ACS) and absorbable collagen sponge alone to evaluate the effect of chitosan on human periodontal ligament fibroblasts (h PDLF) in vitro and on bone formation. The new bone area and defect closure in the chitosan/ACS group were significantly greater than those in the ACS control. Chitosan enhanced the type I collagen synthesis and facilitated the differentiation into osteogenic cells. Chitosan reconstituted with ACS has a significant potential to accelerate the regeneration of bone critical size defects.

In 2013, Arancibia et al (27). Analyzed whether chitosan particles may inhibit the growth of periodontal pathogens and modulate the inflammatory response in human gingival 
fibroblasts. Chitosan particles were generated through ionic gelation. They inhibited the growth of Porphyromonas gingivalis and Aggregatibacter actinomycetemcomitans at $5 \mathrm{mg} / \mathrm{mL}$. Their study showed that chitosan exerts a predominantly anti-inflammatory activity by modulating $\mathrm{PGE}_{2}$ levels, which may be useful in the prevention or treatment of periodontal inflammation.

In 2014, Li et al (28), compared a newly developed chitosan-collagen membrane (CCM) with a standard collagen membrane (SCM) regarding their effects on guided bone regeneration in buccal dehiscence defects around implants in a dog model. After 12 weeks of healing, the defects treated with CCMs documented a similar amount of new bone formation compared with that regenerated with SCMs, showing that the placement of CCMs enhanced bone regeneration, including bone height and volume. The results of the study have shown that the developed CCMs can enhance bone regeneration and could be a candidate for use in guided bone regeneration.

Compared with most of bioabsorbable membranes presently used in clinical practice, chitosan membranes are cheaper and possess better tissue healing effect as it showed more bone formation in animal models. The property of bacteriostasis may reduce bacterial contamination and benefit periodontal tissue regeneration. However, the mechanical properties of pure chitosan membranes prepared in conventional methods might not effectively ensure the function of excluding unwanted tissues and hindered chitosan application at one time.

An outstanding improvement in preparing techniques and methods would overcome this obstacle. For example, blending chitosan with other materials such as HA $(29,30)$. or silica and manufacturing membranes by novel chitosan nanofibers in an electrospinning way are two promising ways. Although both methods need further exploration to make chitosan membranes with good mechanical properties and suitable degradation rate for clinical application in GTR/ GBR, a series of studies have demonstrated the significant and gratifying progress in enhancing mechanical properties of chitosan membranes for a few preparation techniques in vitro and in vivo $(31,32)$.

Further clinical and experimental studies for the use of Chitosan membrane in guided tissue regeneration in different types of periodontal osseous defects are needed, Prolonging the observation period and increasing the sample size maybe of value, Histomorphometric analysis is needed to evaluate the measurements of horizontal and vertical components of furcation areas after using chitosan and other membranes

\section{CONCLUSIONS}

Chitosan membrane is an effective, easy to handle, cheap membrane that can be used for periodontal regeneration of furcation defects, Chitosan membrane showed enhanced bone formation in animal models and more enhanced periodontal tissue regeneration when compared to collagen membrane. Therefore, the findings from this study have indicated that chitosan membrane could be a good substrate candidate as the materials for the GTR/GBR membranes.

\section{CONFLICT OF INTEREST}

We thank dr. Yasser helmy, consultant in biomaterial for supplying the chitosan membrane. All the authors declare to have no conflict of interest with the materials used in the present study.

\section{REFERENCES}

1. Kinane DF. Causation and pathogenesis of periodontal disease. Periodontol 2000 2001; 25: 8-20.

2. Shaila V, Kothiwale P, Anuroopa A, Gajiwala L. A clinical and radiological evaluation of DFDBA with amniotic membrane versus bovine derived xenografts with amniotic membrane in human periodontal grade II furcation defects. Cell Tissue Bank 2009; 10: 317-26.

3. Ponce CH, Domby EM, Anele UY, Schutz JS, Gautam KK, Galyean ML. Effects of bulk density of steam-flaked corn in diets containing wet corn gluten feed on feedlot cattle performance, carcass characteristics, apparent total tract digestibility, and ruminal fermentation. J Anim Sci 2013; 91: 3400-7.

4. Jepsen S, Eberhard J, Herrera D, Needleman I. A systematic review of guided tissue regeneration for periodontal furcation defects. What is the effect of guided tissue regeneration compared with surgical debridement in the treatment of furcation defects? J Clin Periodontol 2002; 29(Suppl 3): 103-16.

5. Gottlow J, Nyman S. Barrier membranes in the treatment of periodontal defects. Curr Opin Periodontol 1996; 3: 140-8.

6. Reynolds MA, Bowers GM. Periodontal regeneration following surgical treatment. Curr Opin Periodontol 1996; 3: 126-39.

7. Preeja C, Sivadas A. Platelet-rich fibrin: Its role in periodontal regeneration. Saudi J Dent Res 2014; 5: 117-22.

8. Wang HL, Cooke J. Periodontal regeneration techniques for treatment of periodontal diseases. Dent Clin North Am 2005; 49: 637-59.

9. Baskbutski JD, Wang HL. Periodontal and endodontic regeneration. J Endod 2009; 35: 321-8.

10. Buser D, Dula K, Belser U, Hirt HP, Berthold H. Localized ridge augmentation using guided bone regeneration. Int $\mathrm{J}$ Periodontics Restorative Dent 1993; 13: 29-45.

11. Schwartzmann M. Use of collagen membranes for guided bone regeneration: A review. Implant Dent 2000; 9: 63-6.

12. Norowski PA, Bumgardner JD. Biomaterial and antibiotic strategies for peri-implantitis. J Biomed Mater Res B Appl Biomater 2008; 88: 530-43.

13. Gomes S, Boulon M-E. Oliveira AL, Leonor IB, Mano JF, Reis RL. Mineralization of chitosan membrane using a double diffusion systemfor bone related applications. Mater Sci Forum 2008; 587: 77-81.

14. Chun X, Chang L, Liuyan M, Changning W, Yaling S. Chitosan as a barrier membrane material in periodontal tissue regeneration. J Biomed Mater Res B Appl Biomater 2012; 100: 1435-43.

15. Muzzarelli RA. Chitins and chitosans for the repair of wounded skin, nerve, cartilage and bone. Carbohydr Polym 2009; 76: 167-82.

16. Cui J, Liang J, Wen Y, Sun X, Li T, Zhang G, et al. In vitro and in vivo evaluation of chitosan/b-glycerol phosphate composite membrane for guided bone regeneration. J Biomed Mater Res Part A 2014; 102: 2911-7.

17. Tatakis DN, Promsudthi A, Wikesjo UME. Devices for periodontal regeneration. Periodontol 2000 1999; 19: 5973.

18. Teng S, Lee E, Wang P, Shin D, Kim H. Three-layered membranes of collagen/hydroxyapatite and chitosan for guided bone regeneration. J Biomed Mater Res B Appl Biomater 2008; 87: 132-8. 
19. Jiang T, Kumbar SG, Nair LS, Laurencin CT. Biologically active chitosan systems for tissue engineering and regenerative medicine. Curr Top Med Chem 2008; 8: 354-64.

20. Wohlfahrt JC, Aass AM, Rønold HJ, Heijl L, Haugen HJ, Lyngstadaas SP. MicroCT and histological analysis of animal experimental Degree II furcation defects treated with porous titanium granules or deproteinized bovine bone J Periodontol 2012; 83: 211-21.

21. Abramoff MD, Magalhaes PJ, Ram SJ. Image Processing with Image J. Biophotonics Int 2004; 11: 36-42.

22. Kotz S, Balakrishnan N, Read CB, Vidakovic B. Encyclopedia of statistical sciences. 2nd ed. Hoboken, N.J.: Wiley-Interscience, 2006.

23. Kirkpatrick LA, Feeney BC. A simple guide to IBM SPSS statistics for version 20.0. Student ed. Belmont, Calif.: Wadsworth, Cengage Learning, 2013.

24. Cacchioli A, Spaggiari B, Ravanetti F, Martini FM, Borghetti P, Gabbi C. The critical sized bone defect: morphological study of bone healing. Ann Fac Medic Vet di Parma 2006; 26:97-110.

25. Hurzeler MB, Quinines CR, Caffesse RG, Schupbach P, Morrison EC. Guided periodontal tissue regeneration in class II furcation defects following treatment with a synthetic bioabsorbable barrier. J Periodontal 1997; 68: 498-505.

26. Pang EK, Paik JW, Kim SK, Jung UW, Kim CS, Cho KS, et al. Effects of chitosan on human periodontal ligament

27. fibroblasts in vitro and on bone formation in rat calvarial defects. J Periodontol 2005; 76: 1526-33.

28. Arancibia R1, Maturana C, Silva D, Tobar N, Tapia C, Salazar JC, et al. Effects of Chitosan Particles in Periodontal Pathogens and Gingival Fibroblasts. J Dent Res 2013; 92: $740-5$.

29. Li X, Wang X, Zhao T, Gao B, Miao Y, Zhang D, et al. Guided bone regeneration using chitosan-collagen membranes in dog dehiscence-type defect model. J Oral Maxillofac Surg 2014; 72: 304.e1-14.

30. Tang SH, Lee EJ, Yoon BH, Shin DS, Kim HE, Oh JS. Chitosan/nanohydroxyapatite composite membranes via dynamic filtration for guided bone regeneration. J Biomed Mater Res A 2009; 88: 569-80.

31. Teng SH, Lee EJ, Wang P, Shin DS, Kim HE. Threelayered mem- branes of collagen/hydroxyapatite and chitosan for guided bone regeneration. J Biomed Mater Res B Appl Biomater 2008; 87: 132-8.

32. Lee EJ, Shin DS, Kim HE, Kim HW, Koh YH, Jang JH. Membrane of hybrid chitosan-silica xerogel for guided bone regeneration. Biomaterials 2009; 30: 743-50.

33. Ku Y, Shim IK, Lee JY, Park YJ, Rhee SH, Nam SH, et al. Chitosan/ poly (L-lactic acid) multilayered membrane for guided tissue regeneration. J Biomed Mater Res A 2009; 90: 766-72. 